$$
\begin{aligned}
& \text { اثر ميدان هاى الكترومغناطيسى بر بيان آلفا_فيتويروتئين در مايع آمنيوتيك جنين موش } \\
& \text { شهين اسمعيلنزاد و فرهاد مشايخى } \\
& \text { كروه زيستشناسى، دانشكده علوم پايه، دانشعاه گيلان } \\
& \text { mashayekhi@guilan.ac.ir مسئول مكاتبات: فرهاد مشايخى، }
\end{aligned}
$$

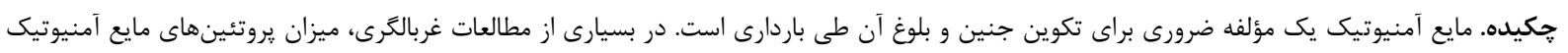

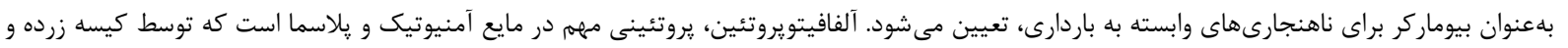

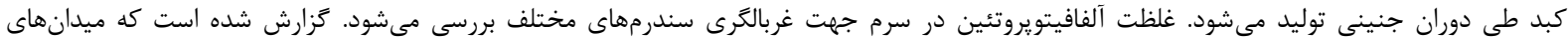

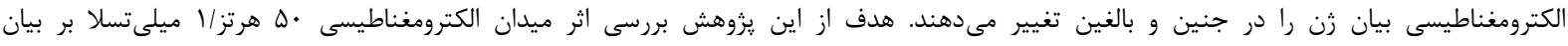

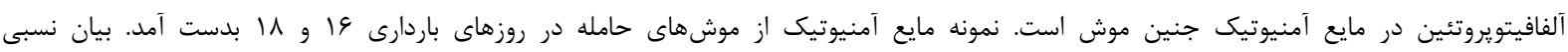

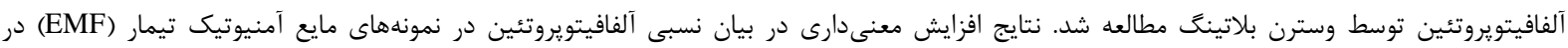

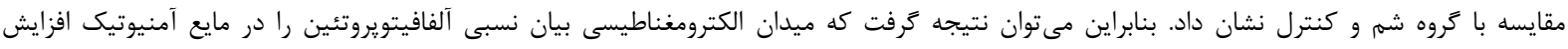

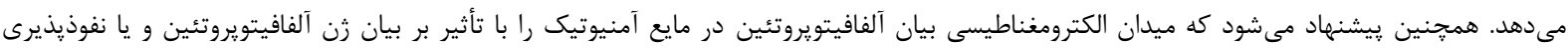

$$
\begin{aligned}
& \text { سدهاى خونى جفتى، تغيير مى دهد. } \\
& \text { وازههاى كليدى. اثرات زيستى، بيان يروتئين، تكوين جنينى، ميدان مغناطيسى، وسترن بلات }
\end{aligned}
$$

\title{
The effects of electromagnetic fields on alpha-fetoprotein expression in the amniotic fluid of mouse embryo
}

\author{
Shahin Esmaeilnezhad \& Farhad Mashayekhi \\ Department of Biology, Faculty of Science, University of Guilan \\ Corresponding Author: Farhad Mashayekhi, mashayekhi@guilan.ac.ir
}

\begin{abstract}
Amniotic fluid (AF) is essential for fetal development and maturation during pregnancy. The levels of proteins in AF have been determined in many studies to screen for potential biomarkers of pregnancy-associated abnormalities. Alpha-fetoprotein (AFP) is a major AF and plasma protein produced by the yolk sac and the liver during the fetal period. APF serum concentrations are commonly used for screening of many syndromes. Electromagnetic fields (EMFs) were reported to change gene expression in the embryo and in adults. The aim of this research was to assess the effects of 50hertz/1millitesla EMFs on AFP expression in the AF in the mouse embryo. AF samples were obtained from pregnant mice in gestational days 16 and 18. AFP relative expression was studied by western blotting. The results of this study showed that AFP relative expression increases in the EMF-treated AF as compared with either SHAM or control groups. It is concluded that EMF increases the AFP relative expression in the AF. It is also suggested that EMF may change the AFP expression in the AF by altering the expression of genes, including AFP, and/or by affecting the permeability of blood barriers.
\end{abstract}

Keywords: biological effects, embryonic development, magnetic field, protein expression, Western blot 
يروتئين در سرم جنين است كه در ماه سوم باردارى غلظت آن

به حداكثر r ميلى كرم در ميلىليتر مىرسد (Tomasi, 1977).

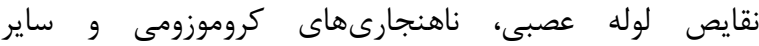

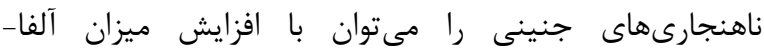

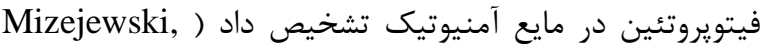
2002). بين تكثير سلولى و توليد آلفا-فيتويروتئين رابطه نزديكى وجود دارد (He \& Keel, 1994)؛ لذا آلفا-فيتوبروتئين

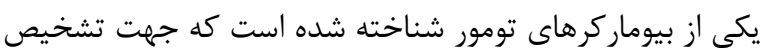
و نظارت بر درمان تومورهاى بدخيم سلولهاى بنيادى و بدخيمىهاى سلولهاى كبدى مورد استفاده قرار مئى آنيرد

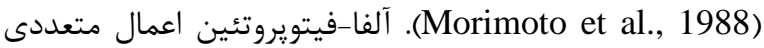

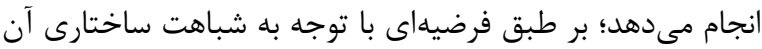

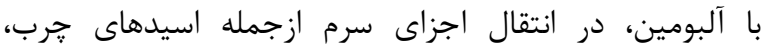

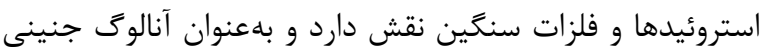
آلبومين عمل مى كند (Mizejewski, 2002). آلفا-فيتويروتئين

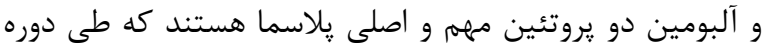
تكوين در مايع مغزى-نخاعى يافت مىشوند. نشان داده داد شده

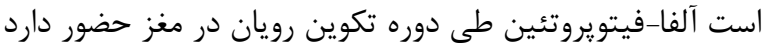

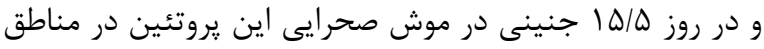

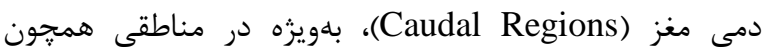
هييوتالاموس، آميخدال و هييوكامٍ كه در اين زمان در حال

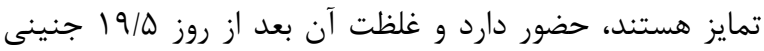

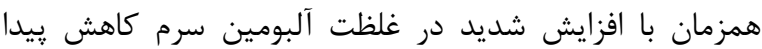

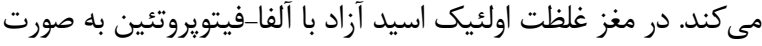

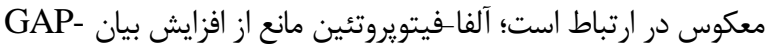
43 ناشى از حضور اولئيكاسيد در سلولهاى عصبى مىشود كه نشان أنسان مىدهد اين يروتئين با مهار اثر نوروتروفيك اولئيك اسيد، تأثير آلبومين سرم بر رشد مغز را تعديل مى كند ( García-García et

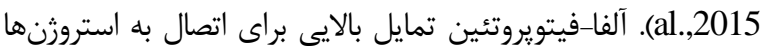

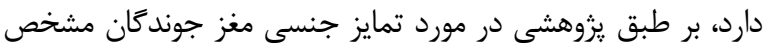
شده است كه اين بروتئين از مغز مادهها در برابر اثرات استرورن

محافظت مى كند (Bakker et al., 2006). بسيارى از مطالعات تأثيرات ميدانهاى الكترومغناطيسى را بر

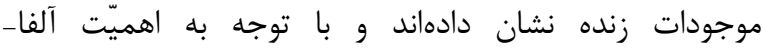

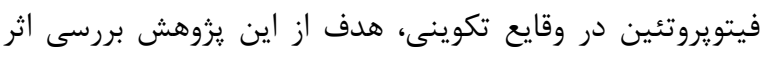
ميدان الكترومغناطيسى 1 ميلىتسلا (•ه هرتز) بر بيان آلفافيتويروتئين مايع آمنيوتيك جنين موش است.

$$
\text { مواد و روش ها }
$$

تهييه نمونههاى مايع آمنيوتيك
انسانها به ميزان زيادى در محل كار و منازل در معرض انواع

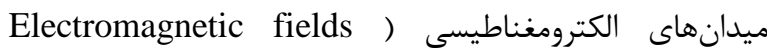
قرار دارند؛ از اينرو ايمنى در برابر اين ميدانها به

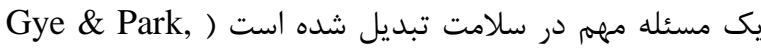

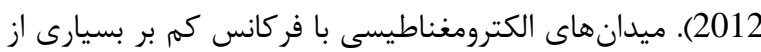
عملكردهاى سلولى ازجمله بيان زن، تكثير، تمايز سلولى و

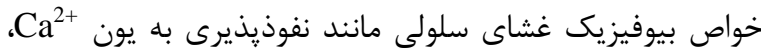

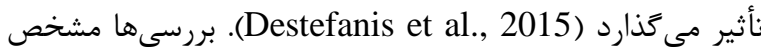

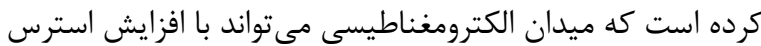

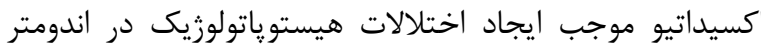

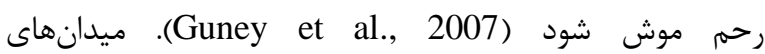
الكترومغناطيسى با فركانس كم بر بافت نفوذ مى كند و بر اعمال

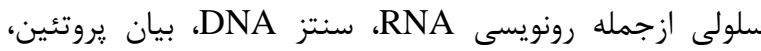

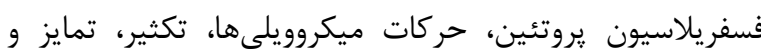
آيايتوز سلولى تأثير مى كذارد ( Wei et al., 2016; Martens et

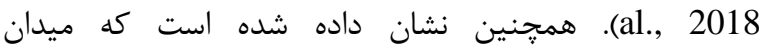
الكترومغناطيسى باعث كوتاه شدن دوره جنينى و تغيير در غلظت برخى هورمونها در سرم خون جنين جوجه مىشود

.(Pawlak et al., 2018)

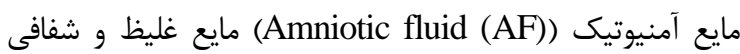
است كه حفره آمنيوتيك را ير مى كند. مايع آمنيوتيك براى تكوين مايع إنائ

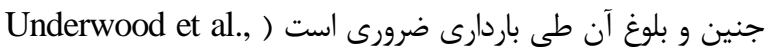
2005; Tong et al., 2009 موضوع مهم در فيزيولوزى جنين و جفت و ابزارى مهم براى العيونائ

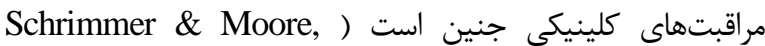

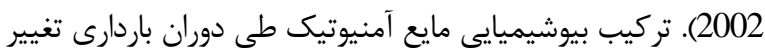
مى كند و بروتئينهاى موجود در اين مايع تغييرات فيزيولوزيك و

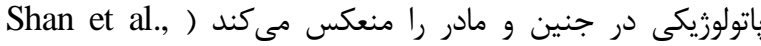
2012). بررسىها نشان داده است كه جنين ونين منبع اصلى تركيبات

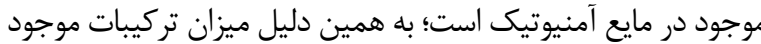

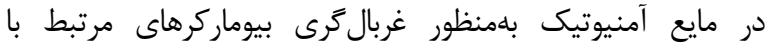
ناهنجارى هاى دوران باردارى در بسيارى از مطالعات مورد بررسى قرار كرفته است (Tong et al., 2009). آلفا-فيتويروتئين (Alpha-Fetoprotein (AFP)) كليكويروتئينى

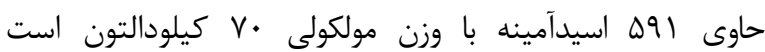
(Mizejewski, 2001). اين يروتئين، يروتئين اصلى پِلاسماى

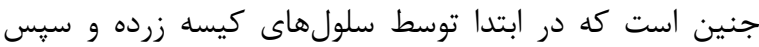

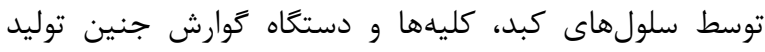

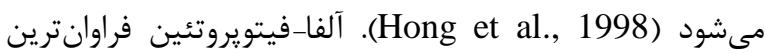


شد. بيان نسبى آلفا-فيتويروتئين توسط روش وسترن بلاتينگ

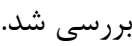

\section{انجام روش وسترن بلاتينَ}

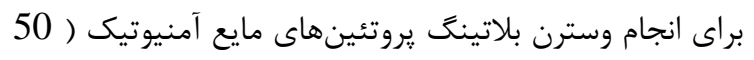

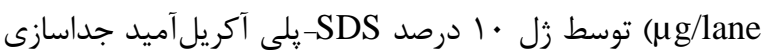

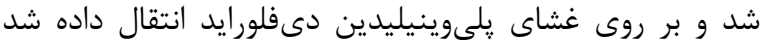

(Bio-Rad Laboratories Ltd. Hertfordshire, UK)

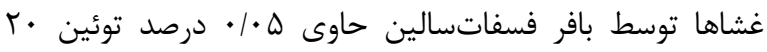
(Tween 20)

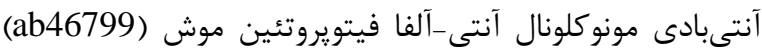
(رقت: Abcam, Cambridge, UK) مونوكلونال آنتى-بتا توبولين موش (بهعنوان كنترل بارگزارى) (1:10,000 dilution) (Abcam plc, Cambridge, UK) تيمار شد و سيس با آنتىبادى ثانويه كنروكه شده با يراكسيداز

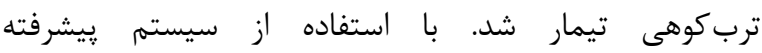
Chemiluminescence Western blotting detection system يروتئينهاى Immunoreactive، قابل مشاهده شدند

.(Amersham Pharmacia Biotech, Piscataway, NJ) آناليز دانسيتومترى با اسكن ايمونوبلاتها و آناليز تصاوير انجام

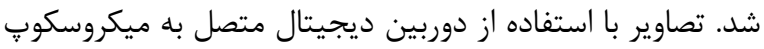
(Pixel Cooled CCD Camera, Princeton Instruments) كرفته شد. آناليز تصاوير و اندازهيرى شدت و مقادير باندهاى Metaview V. يروتئينى با استفاده از نرمافزار تحليل

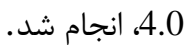

آناليز آمارى

نتايج ارائه شده به صورت "ميانكَين \ خطاى استاندارد

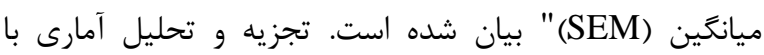
استفاده از آزمون آناليز واريانس يك طرفه (ANOVA) انجام استيام شده است تا اختلاف بين گروهها بررسى شود. تنها مقادير با باليا ه • P • > معنى دار در نظر كرفته شده است.

نتايج بيان نسبى آلفا-فيتويروتئين در مايع آمنيوتيك در روزهاى

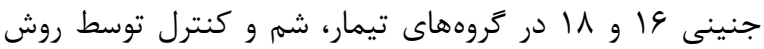
وسترن بلاتينَ تعيين شده است (شكل ()). بيان نسبى كروه

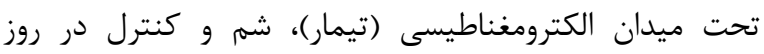

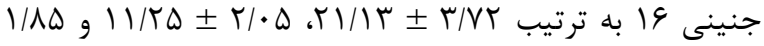

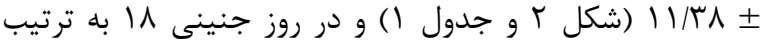
泟 r و جدول (1). افزايش معنىدارى در بيان نسبى آلفا-
موشهاى آزمايشكاهى نزاد Balb/c از انيستيتو پاستور تهران

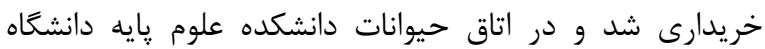

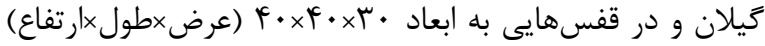

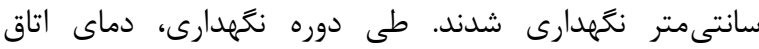

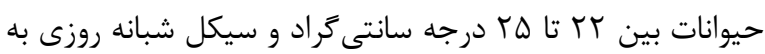

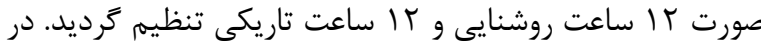
طى اين دوره، غذاى مخصوص موش از شركت بهيرور واقع در تهران خريدارى شد.

جهت جفتخيرى، موشهاى نر و ماده به صورت تصادفى انتخاب و به مدت · ا ساعت در طول شب در يك قفس قرار داد داده شدند. مشاهده پِلاك وازينال بهعنوان روز اول جنينى (E0) درنظركرفته شد. همه روشهاى بلهكاركرفته شده مطابق قانون

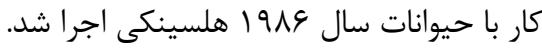

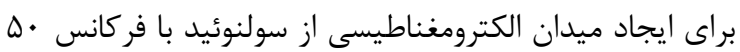

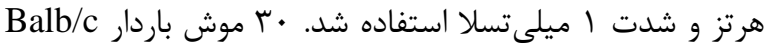
در دو روز جنينى ها و البه سه كروه تيمار (EMF) كنترل (Control)

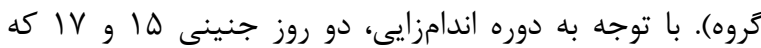
مايع آمنيوتيك توليد شده داراى حجم مناسب براى سناى سنجش

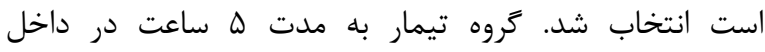
سولنوئيد روشن (•ه هرتز / إبلى ميلىتسلا) در معرض ميدان الكترومغناطيسى قرار داده شد. در محيط زندكى معمولىترين

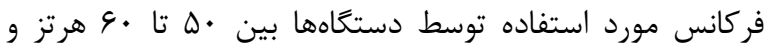

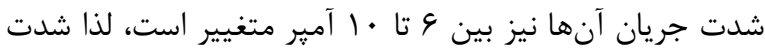

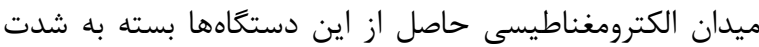
جريان و فاصله از دستخاه بين 1 تا 1 ميلىتسلا متغيير است داصنا

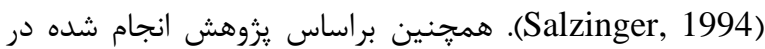

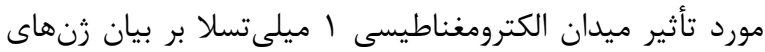

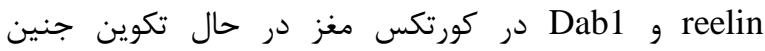

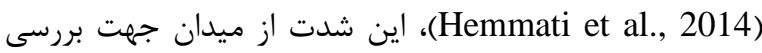

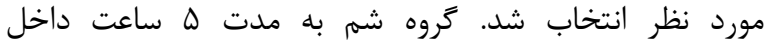

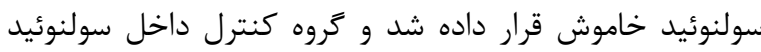

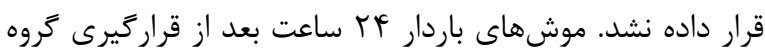
تيمار در معرض ميدان الكترومغناطيسى، در روزهاى جنينى 19

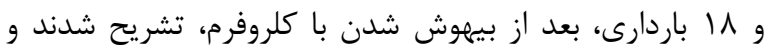

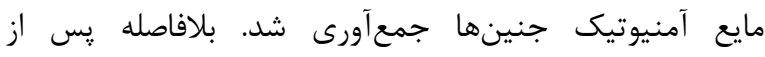
جمعآورى مايع آمنيوتيك، جهت جداسازى باقى ماندههاى سلولى

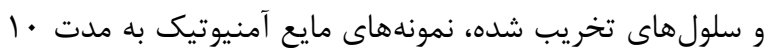

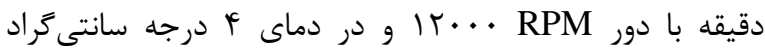

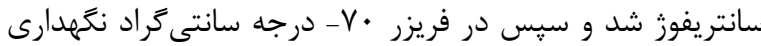




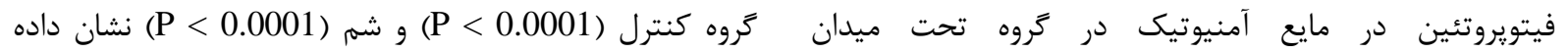

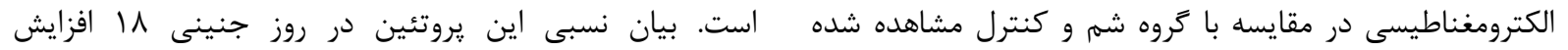

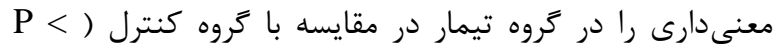

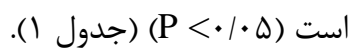
نتايج اين مطالعه نشان داده است كه بيان نسبى آلفا-

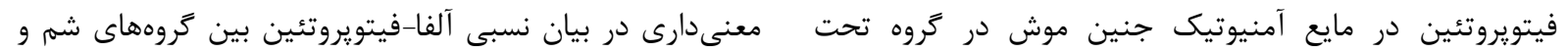

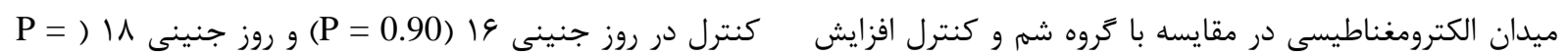
(0.84) مشاهده نشده است.

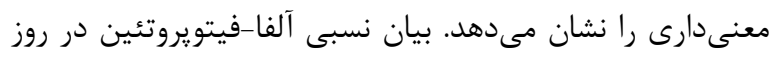

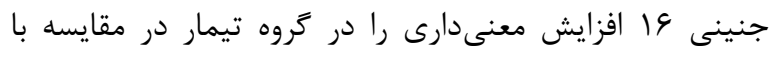

\section{Day 16}

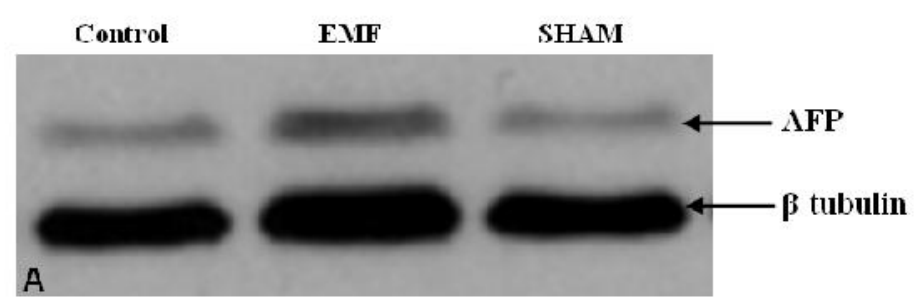

Day 18

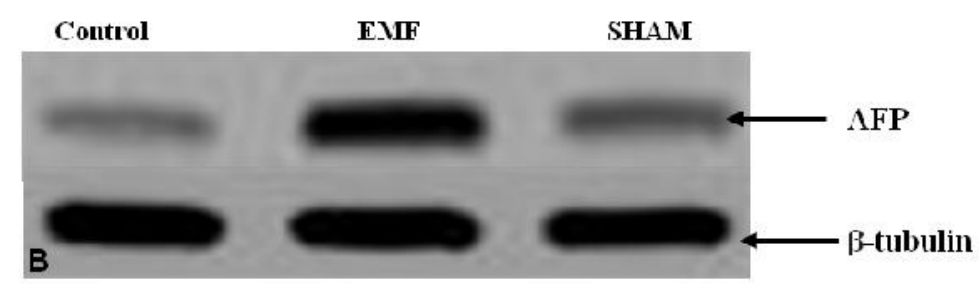

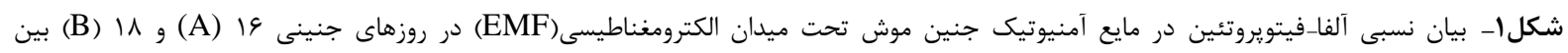

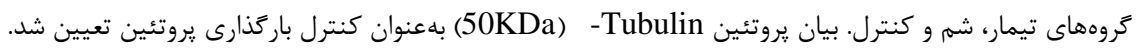

Fig. 1. Relative expression of Alpha-fetoprotein in amniotic fluid in the mouse embryo under the electromagnetic field (EMF) on embryonic days 16 (A) and 18 (B) between control, SHAM and EMF-treated groups. The expression of $\beta$ tubulin $(50 \mathrm{KDa})$ protein was determined as a control of protein loading.

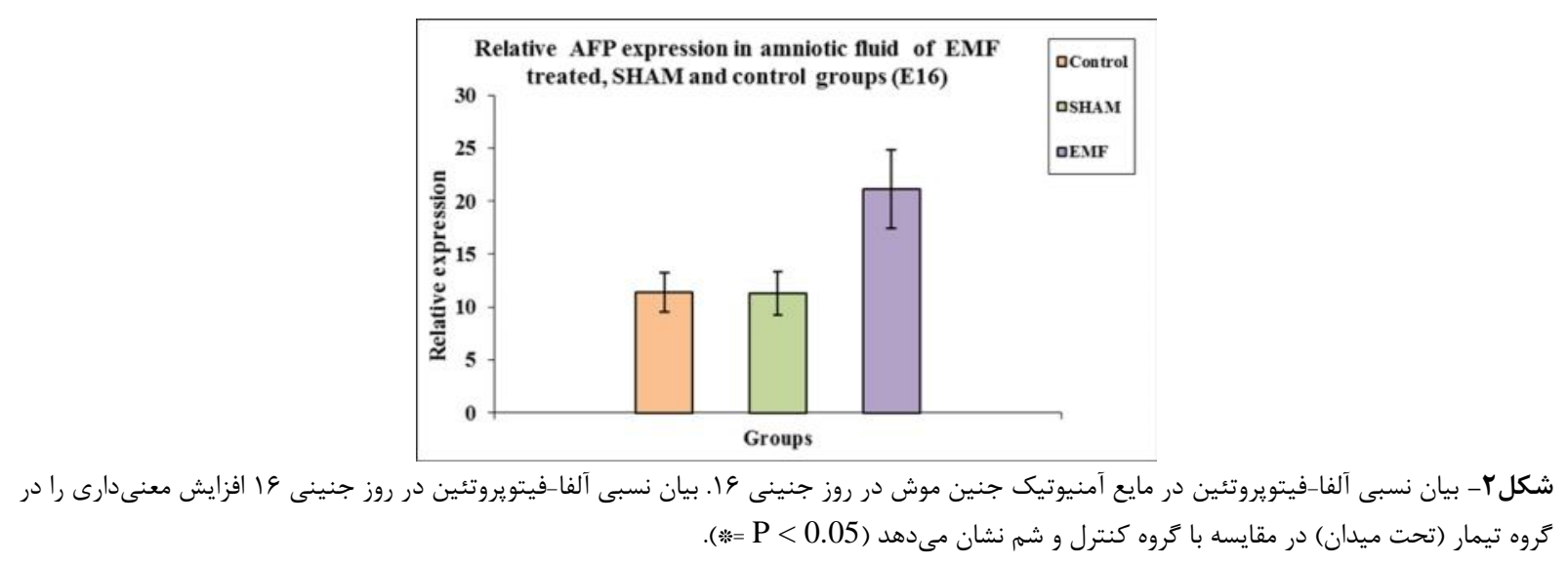

Fig. 2. Alpha-fetoprotein relative expression in amniotic fluid in the mouse embryo on embryonic day 16. The relative expression of Alpha-fetoprotein in the embryonic day 16 showed a significant increase in the emf-treated group (under the field) as compared with the control and SHAM groups $(*=\mathrm{P}<0.05)$. 


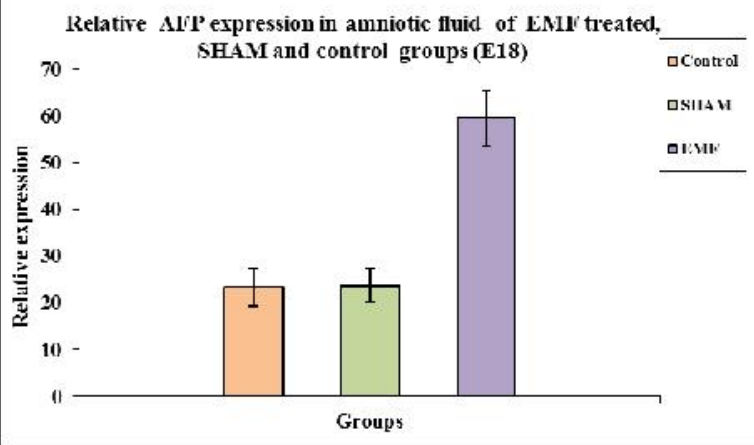

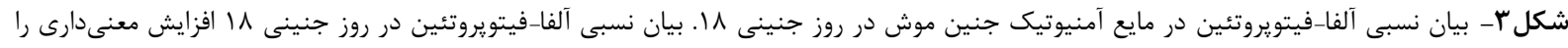

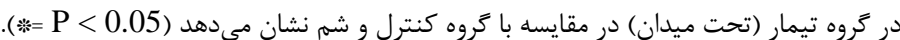

Fig. 3. Alpha-fetoprotein relative expression in amniotic fluid in the mouse embryo on embryonic day 18. The relative expression of Alpha-fetoprotein in the embryonic day 18 showed a significant increase in the emf-treated group (under the field) compared with the control and SHAM groups $(*=\mathrm{P}<0.05)$.

جدولا- بيان نسبى آلفا-فيتويروتئين در مايع آمنيوتيك جنين موش در روز جنينى 19 و و 11.

Table 1. Relative expression of Alpha-fetoprotein in amniotic fluid in the mouse embryo on embryonic days 16 and 18.

\begin{tabular}{|c|c|c|c|c|c|}
\hline \multicolumn{2}{|c|}{} & Average & SD & \multicolumn{2}{c|}{ P value } \\
\hline \multirow{2}{*}{$\begin{array}{c}\text { Embryonic } \\
\text { day 16 }\end{array}$} & EMF & 21.13 & 3.72 & EMF - Control & $1.11 \times 10^{-05}$ \\
\cline { 2 - 6 } & SHAM & 11.25 & 2.05 & EMF - SHAM & $1.24 \times 10^{-05}$ \\
\cline { 2 - 6 } & Control & 11.38 & 1.85 & SHAM - Control & 0.90 \\
\hline \multirow{2}{*}{$\begin{array}{c}\text { Embryonic } \\
\text { day 18 }\end{array}$} & EMF & 59.50 & 5.95 & EMF - Control & $8.82 \times 10^{-10}$ \\
\cline { 2 - 6 } & Control & 23.25 & 3.92 & SHAM - Control & $7.24 \times 10^{-10}$ \\
\cline { 2 - 6 } & & 23.63 & 3.58 & EMF - SHAM & 0.84 \\
\hline
\end{tabular}

كاهش در بيان زنهايى از جمله زنهاى CCL27 , DNMT3A

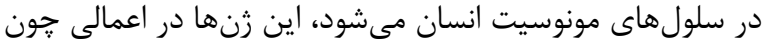

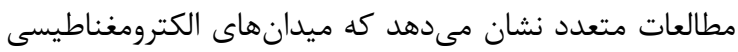
متابوليسم، فرايندهاى فيزيولوزيك، انتقال سيكنال، تكوين، ياسخ بر روى موجودات زنده در حال رشد تأثير دارند. كاهش تعدان مانداد به تحريك و همئوستاز سلولى دخيل هستند ( Lupke et al.,

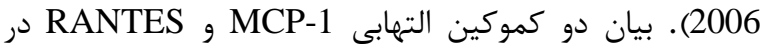
مونوسيتهاى انسانى قراركرفته در معرض ميدان المينان 1 ميلىتسلا

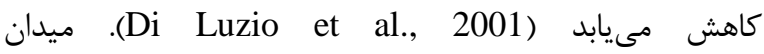
الكترومغناطيسى موجب افزايش بيان C-fos در محيط كشت

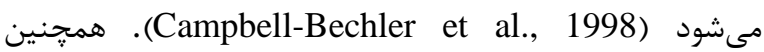
مشخص شده است كه ميدان الكترومغناطيسى / / ميلى متسلا با افزايش بيان mRNA زن

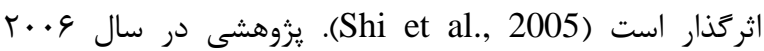
مشخص كرده است كه ميدان الكترومغناطيسى فر كانس راديويى، دأس

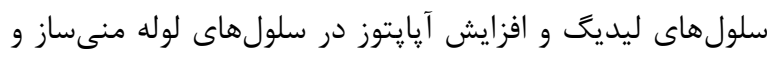

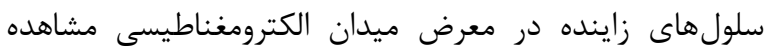
شده است (Saygin et al., 2011). طبق مطالعات انجام اندام شده ميدان الكترومغناطيسى در موش صحرايى موجب كاهش

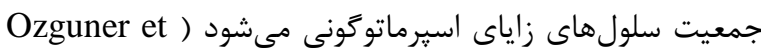

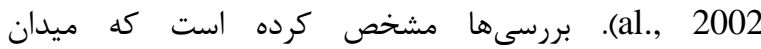
الكترومغناطيسى روى لانهزَينى و تكوين جنين اثر مى مَذارد

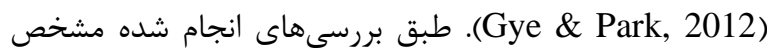

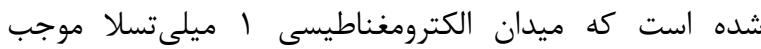
افزايش بيان زنهايى جون IL20RA، 
مى توان نتيجه كرفت ميدان الكترومغناطيسى با تغيير در بيان

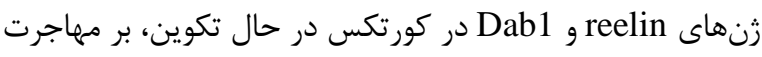

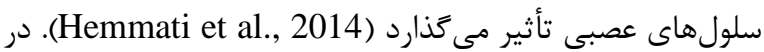

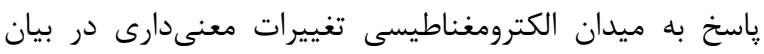

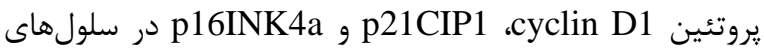
مايع آمنيوتيك مشاهده شده است. اين يروتئينها در خرخه

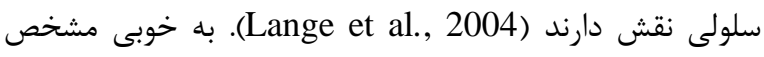
شده است كه سطح بيان آلفا-فيتويروتئين با بسيارى تغييرات

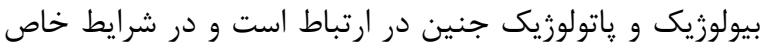

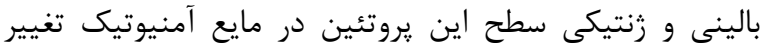
مى كند (Darouich et al., 2015).

\section{نتيجه كيرى}

در اين تحقيق نشان داده شده است كه ميدان الكترومغناطيسى

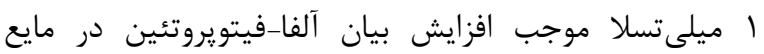

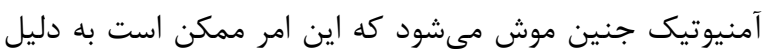

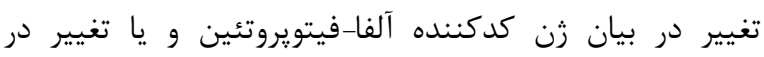
نفوذيذيرى اين يروتئين در سد خونى-جفتى يا جنينى-مادرى بوده باشد. براى نتيجهيرى صحيحتر لازم است ميزان بيان آلفأ-

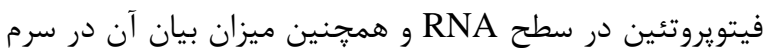
خون جنين و مادر مطالعه شود.

\section{سياسگزارى}

اين مطالعه در گروه زيستشناسى دانشكده علوم يايه، دانشخاه

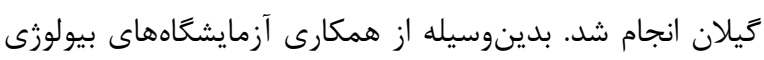

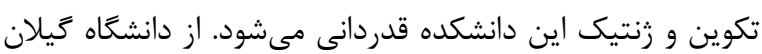

$$
\text { جهت حمايت مالى تشكر مىشود. }
$$

\section{REFERENCES}

Bakker, J., De Mees, C., Douhard, Q., Balthazart, J., Gabant, P., Szpirer, J. \& Szpirer, C. 2006. Alphafetoprotein protects the developing female mouse brain from masculinization and defeminization by estrogens. Nat. Neurosci. 9: 220-226.

Bortkiewicz, A. 2001. A study on the biological effects of exposure mobile-phone frequency EMF. Med. Pr. 52: 101-106.

Campbell-Beachler, M., Ishida-Jones, T., Haggren, W. \& Phillips, J.L. 1998. Effect of $60 \mathrm{~Hz}$ magnetic field exposure on $c$-fos expression in stimulated PC12 cells. Mol. Cell Biochem. 189: 107-111.

Darouich, A.A., Liehr, T., Weise, A., Schlembach, D., Schleußner, E., Kiehntopf, M. \& Schreyer, I. 2015. Alpha-fetoprotein and its value for predicting pregnancy outcomes - a re-evaluation. J. Prenat. Med. 9: 18-23.

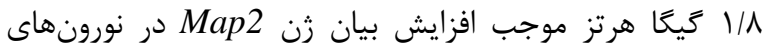

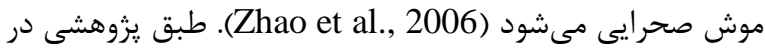

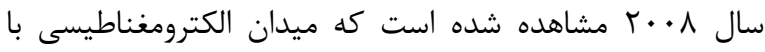

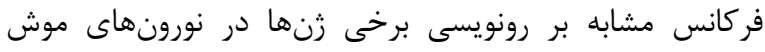

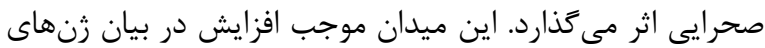

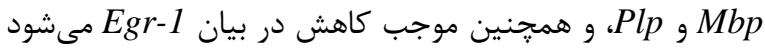

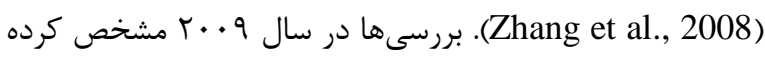

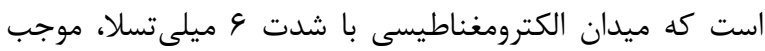

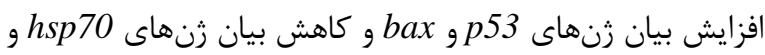
(Tenuzzo et al., 2009).

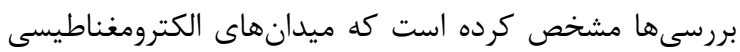

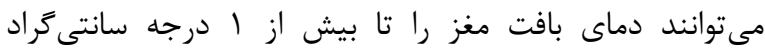

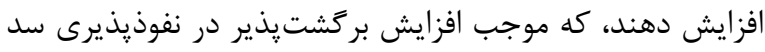

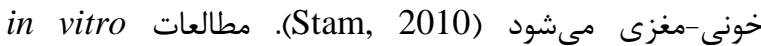
مشخص كرده است كه ميدانهاى الكترومغناطيسى تغييراتى راني

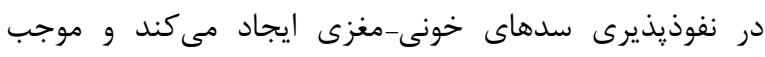

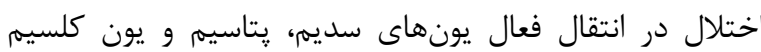

توسط غشاى سلولى مى شود (Bortkiewicz, 2001).

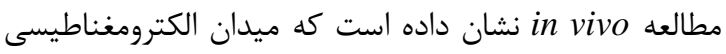

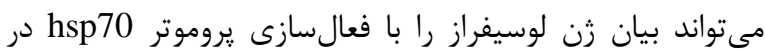
ماهيجههاى جهارسر موش تغيير دهد ( Rodríguez-De la Fuente et al., 2012 غلظت يلاسمايى كلسترول و فسفولييِد مى شود و بيان mRNA

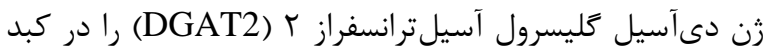

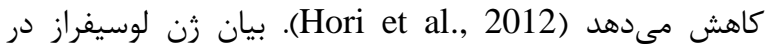

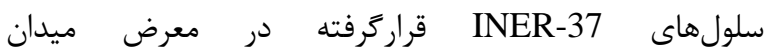

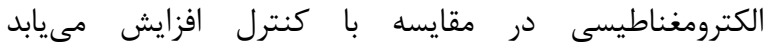
(Heredia-Rojas et al., 2010). مشخص شده است كه ميدان الكترومغناطيسى موجب القاء تغييرات مولكولى طى تمايز سلولهاى بنيادى عصبى جنينى مىشود كه ممكن است مرتبط با مكانيسمهاى يس از رونويسى تنظيمكنينده همئوستازسلولى

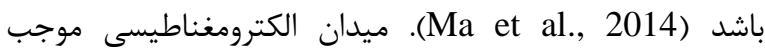
كاهش سطح بيان c-Fos و در كبد جنين مرغ مىشود درحالىكه بيان GAPDH بدون تغيير باقى مىماند (Lahijani et al., 2011)

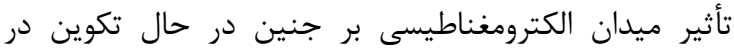
بسيارى از مطالعات نشان داده شده است. پيشنههاد شده است كه

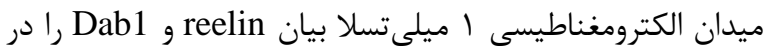
كورتكس مغز در حال تكوين جنين افزايش مى مدهد. اين دو زئل در مهاجرت سلولهاى عصبى نقش مهمى را ايفا مى كنند كه 
Destefanis, M., Viano, M., Leo, C., Gervino, G., Ponzetto, A. \& Silvagno, F. 2015. Extremely low frequency electromagnetic fields affect proliferation and mitochondrial activity of human cancer cell lines. Int. J. Radiat. Biol. 91: 964-972.

Di Luzio, S., Felaco, M., Barbacane, R.C., Frydas, S., Grilli, A., Castellani, M.L., Macrì, M.A., Di Gioacchino, M., Merlitti, D., De Lutiis, M.A., Masci, S., Di Giulio, C., Cacchio, M. \& Reale, M. 2001. Effects of $50 \mathrm{~Hz}$ sinusoidal electromagnetic fields on MCP-1 and RANTES generated from activated human macrophages. Int. J. Immunopathol. Pharmacol. 14: 169-172.

García-García, A.G., Polo-Hernández, E., Tabernero, A. \& Medina, J.M. 2015. Alpha-fetoprotein (AFP) modulates the effect of serum albumin on brain development by restraining the neurotrophic effect of oleic acid. Brain Res. 1624: 45-58.

Guney, M., Ozguner, F., Oral, B., Karahan, N. \& Mungan, T. 2007. $900 \mathrm{MHz}$ radiofrequency-induced histopathologic changes and oxidative stress in rat endometrium: protection by vitamins $\mathrm{E}$ and $\mathrm{C}$. Toxicol. Ind. Health. 23: 411-420.

Gye, M.C. \& Park, C.J. 2012. Effect of electromagnetic field exposure on the reproductive system. Clin. Exp. Reprod. Med. 39: 1-9.

He, Y. \& Keel, B.A. 1994. Biochemical characterization of bovine alpha-fetoprotein and comparison with human alpha-fetoprotein. Comp. Biochem. Physiol. Biochem. Mol. Biol. 108: 327-336.

Hemmati, M., Mashayekhi, F., Firouzi, F., Ashori, M. \& Mashayekhi, H. 2014. Effects of electromagnetic fields on reelin and Dab1 expression in the developing cerebral cortex. Neurol. Sci. 35: 1243-1247.

Heredia-Rojas, J.A., Rodríguez de la Fuente, A.O., Alcocer González, J.M., Rodríguez-Flores, L.E., Rodríguez-Padilla, C., Santoyo-Stephano, M.A., Castañeda-Garza, E. \& Taméz-Guerra, R.S. 2010. Effect of $60 \mathrm{~Hz}$ magnetic fields on the activation of hsp70 promoter in cultured INER-37 and RMA E7 cells. In Vitro Cell Dev. Biol. Anim. 46: 758-763.

Hong, S.M., Yu, E., Ahn, H. \& Kim, O.J. 1998. Alphafetoprotein producing renal cell carcinoma: a case report. J. Korean Med. Sci. 13: 321-324.

Hori, T., Harakawa, S., Herbas, S.M., Ueta, Y.Y., Inoue, N. \& Suzuki, H. 2012. Effect of $50 \mathrm{~Hz}$ electric field in diacylglycerol acyltransferase mRNA expression level and plasma concentration of triacylglycerol, free fatty acid, phospholipid and total cholesterol. Lipids Health Dis. 11: 68-73.

Lahijani, M.S., Farivar, S. \& Khodaeian, M. 2011. Effects of $50 \mathrm{~Hz}$ electromagnetic fields on the histology, apoptosis, and expression of $c$-Fos and $\beta$-catenin on the livers of preincubated white Leghorn chicken embryos. Electromagn. Biol. Med. 30: 158-169.

Lange, S., Viergutz, T. \& Simkó, M. 2004. Modifications in cell cycle kinetics and in expression of G1 phaseregulating proteins in human amniotic cells after exposure to electromagnetic fields and ionizing radiation. Cell Prolif. 37: 337-349.

Lupke, M., Frahm, J., Lantow, M., Maercker, C., Remondini, D., Bersani, F. \& Simkó, M. 2006. Gene expression analysis of ELF-MF exposed human monocytes indicating the involvement of the alternative activation pathway. Biochim. Biophys. Acta. 1763: 402412.

Ma, Q., Deng, P., Zhu, G., Liu, C., Zhang, L., Zhou, Z., Luo, X., Li, M., Zhong, M., Yu, Z., Chen, C. \& Zhang, Y. 2014. Extremely low-frequency electromagnetic fields affect transcript levels of neuronal differentiation-related genes in embryonic neural stem cells. PLoS One. 9: e90041.

Martens, A.L., Reedijk, M., Smid, T., Huss, A., Timmermans, D., Strak, M., Swart, W., Lenters, V., Kromhout, H., Verheij, R., Slottje, P. \& Vermeulen, R.C.H. 2018. Modeled and perceived RF-EMF, noise and air pollution and symptoms in a population cohort. Is perception key in predicting symptoms? Sci. Total Environ. 639: 75-83.

Mizejewski, G.J. 2001. Alpha-fetoprotein structure and function: relevance to isoforms, epitopes, and conformational variants. Exp. Biol. Med. 226: 377-408.

Mizejewski, G.J. 2002. Biological role of $\alpha$-fetoprotein in cancer: prospects for anticancer therapy. Expert Rev. Anticancer Ther. 2: 709-735.

Morimoto, H., Tanigawa, N., Inoue, H., Muraoka, R., Hosokawa, Y. \& Hattori, T. 1988. Alpha-fetoproteinproducing renal cell carcinoma. Cancer 61: 84-88.

Ozguner, I.F., Dindar, H., Yagmurlu, A., Savas, C., Gokcora, I.H. \& Yucesan, S. 2002. The effect of electromagnetic field on undescended testis after orchiopexy. Int. Urol. Nephrol. 33: 87-93.

Pawlak, K., Nieckarz, Z., Sechman, A., Wojtysiak, D., Bojarski, B. \& Tombarkiewicz, B. 2018. Effect of a $1800 \mathrm{MHz}$ electromagnetic field emitted during embryogenesis on chick development and hatchability. Anat. Histol. Embryol. 47: 222-230.

Rodríguez-De la Fuente, A.O., Alcocer-González, J.M., Heredia-Rojas, J.A., Rodríguez-Padilla, C., Rodríguez-Flores, L.E., Santoyo-Stephano, M.A., Castañeda-Garza, E. \& Taméz-Guerra, R.S. 2012. Effect of $60 \mathrm{~Hz}$ electromagnetic fields on the activity of hsp70 promoter: an in vivo study. Cell Biol. Int. Rep. 19: e00014.

Salzinger, k. 1994. Behavioral effects of electromagnetic fields in animal. Biological effects of Electric and Magnetic fields. New York Academic Press, $1^{\text {st }}$ ed. pp: 315-319.

Saygin, M., Caliskan, S., Karahan, N., Koyu, A., Gumral, N. \& Uguz, A. 2011. Testicular apoptosis and histopathological changes induced by a $2.45 \mathrm{GHz}$ electromagnetic field. Toxicol. Ind. Health. 27: 455-463.

Schrimmer, D.B. \& Moore, T.R. 2002. Sonographic evaluation of amniotic fluid volume. Clin. Obstet. Gynecol. 45: 1026-1038.

Shan, L., Fan, Y., Li, H., Liu, W., Gu, H., Zhou, F. \& Yuan, Z. 2012. Proteomic analysis of amniotic fluid of pregnant rats with spina bifida aperta. J. Proteomics. 75: 1181-1189.

Shi, Y., Bao, X., Huo, X., Shen, Z. \& Song, T. 2005. 50-Hz magnetic field (0.1-mT) alters $c$-fos mRNA expression of early post implantation mouse embryos and serum estradiol levels of gravid mice. Birth Defects Res. B. Dev. Reprod. Toxicol. 74: 196-200. 
Stam, R. 2010. Electromagnetic fields and the blood-brain barrier. Brain Res. Rev. 65: 80-97.

Tenuzzo, B., Vergallo, C. \& Dini, L. 2009. Effect of 6mT static magnetic field on the bcl-2, bax, p53 and hsp70 expression in freshly isolated and in vitro aged human lymphocytes. Tissue Cell. 41: 169-179.

Tomasi Jr, T.B. 1977. Structure and function of alphafetoprotein. Annu. Rev. Med. 28: 453-465.

Tong, X.L., Wang, L., Gao, T.B., Qin, Y.G., Qi, Y.Q. \& Xu, Y.P. 2009. Potential function of amniotic fluid in fetal development novel insights by comparing the composition of human amniotic fluid with umbilical cord and maternal serum at mid and late gestation. J. Chin. Med. Assoc. 72: 368-373.

Underwood, M.A., Gilbert, W.M. \& Sherman, M.P. 2005. Amniotic fluid: not just fetal urine anymore. J. Perinatol. 25: $341-348$
Wei, J., Tong, J., Yu, L. \& Zhang, J. 2016. EMF protects cardiomyocytes against hypoxia-induced injury via heat shock protein 70 activation. Chem. Biol. Interact. 248: 8-17.

Zhang, S.Z., Yao, G.D., Lu, D.Q., Chiang, H. \& Xu, Z.P. 2008. Effect of $1.8 \mathrm{GHz}$ radiofrequency electromagnetic fields on gene expression of rat neurons. Zhonghua Lao Dong Wei Sheng Zhi Ye Bing Za Zhi 26: 449-452.

Zhao, R., Zhang, S.Z., Yao, G.D., Lu, D.Q., Jiang, H. \& Xu, Z.P. 2006. Effect of $1.8 \mathrm{GHz}$ radiofrequency electromagnetic fields on the expression of microtubule associated protein 2 in rat neurons. Zhonghua Lao Dong Wei Sheng Zhi Ye Bing Za Zhi 24: 222-225.

How to cite this article:

Esmaeilnezhad, Sh. \& Mashayekhi, F. 2020. The effects of electromagnetic fields on alpha-fetoprotein expression in the amniotic fluid of mouse embryo. Nova Biologica Reperta 7: 169-176. (In Persian).

اسمعيلنزاد، ش. و مشايخى، ف. وqبا. اثر ميدانهاى الكترومغناطيسى بر بيان آلفا-فيتويروتئين در مايع آمنيوتيك جنين موش. يافتهاى نوين در علوم 